\title{
COMPARATIVE CLEAVAGE OF tert-BUTOXYCARBONYL
}

\section{AND BENZYLISOPROPOXYCARBONYL DERIVATIVES}

OF AMINO ACIDS

V.F. Pozdnev

UDC 547.493

We have previously shown [1] that the reaction of salts of amino acids with di-2-benzylisopropyl pyrocarbonate forms N-2-benzylisopropoxycarbonyl derivatives of amino acids (N-BPOC-amino acids). The present paper gives the results of an investigation of the conditions for the removal of the N-BPOC group and a comparison of the stability of the N-tert-butoxycarbonyl (BOC) and BPOC groups under the action of the reagents generally used for removing the N-BOC protection of amino acids.

To solve this problem, we investigated the time for the complete cleavage of BOC-and BPOC-glycines under the action of a solution of trifluoroacetic acid in methylene chloride (1:1), of a $1 \mathrm{~N}$ solution of hydrogen chloride in glacial acetic acid, and of a $1 \mathrm{~N}$ solution of boron trifluoride etherate in glacial acetic acid [2].

Weighed samples of BOC- or BPOC-glycine $(1 \mathrm{mg})$ were dissolved in $1 \mathrm{ml}$ of cleavage reagent, and after predetermined intervals $0.1-\mathrm{ml}$ samples of the reaction mixture were taken and were mixed with 0.1 $\mathrm{ml}$ of a $1 \mathrm{~N}$ solution of $\mathrm{NaOH}$ in methanol to stop the reaction. Then the sample no longer containing the initial BOC- or BPOC-glycine was determined chromatographically [Silufol plates, benzene-chloroformacetic acid $(20: 20: 2)$, and the time of taking this sample (after refining it in a repeat experiment) was taken as the time of complete cleavage of the corresponding derivative. It was established in preliminary experiments that the spots of BOC- and BPOC-glycines at concentrations of $1 \%$ of the initial amount are clearly shown on a thin-layer chromatogram by ninhydrin at $120^{\circ} \mathrm{C}$. Consequently, the completeness of the cleavage of the $\mathrm{N}$-substituted derivatives found corresponds to not less than $99 \%$ of the initial amount (Table 1). The results obtained show that under identical conditions the amount of time required for the complete removal of the N-BPOC protective group is approximately ten times that for the BOC group, although in both cases the reaction begins immediately after the mixing of the reagents (glycine appears in samples taken 1 min after mixing).

Similar results were obtained in the cleavage of the BOC and BPOC derivatives of leucine.

TABLE 1. Time of Complete Removal of the N-Protective Groupings from Glycine, $\min$

\begin{tabular}{|c|c|c|c|}
\hline Reagent & $\begin{array}{l}\mathrm{CP}_{z} \mathrm{COOH}- \\
-\mathrm{CH}_{2} \mathrm{Cl}_{2} \mathrm{I}: 1\end{array}$ & in $\mathrm{CH}_{3} \mathrm{CUOH}$ & $\begin{array}{l}1 \mathrm{~N} \mathrm{BF}_{2} \cdot \mathrm{C}_{4} \mathrm{H}_{3} \\
\text { in } \mathrm{CH}_{3} \mathrm{COOH}\end{array}$ \\
\hline $\begin{array}{l}B O C- \\
B P O C\end{array}$ & $\begin{array}{c}5-6 \\
30-32\end{array}$ & $\begin{array}{c}5-6 \\
40-45\end{array}$ & $\begin{array}{c}7-8 \\
55-60\end{array}$ \\
\hline
\end{tabular}

\section{LITERATURE CITED}

1. V. F. Pozdnev, Khim. Prirodn. Soedin., 384 (1971).

2. R. G. Niskey, L. M. Beacham, V. G. Matl, Y. N. Smith, E. B. Williams, A. M. Thomas, and E. T. Wolters, J. Org. Chem., 36, 788 (1971).

Institute of Biological and Medicinal Chemistry, Academy of Medical Sciences of the USSR. Translated from Khimiya Prirodnykh Soedinenii, No. 3, pp. 402-403, May-June, 1972. Original article submitted January 16, 1972.

- 1974 Consultants Bureau, a division of Plenum Publishing Corporation, 227 W'est 17th Street, New York, N. Y. 10011. No part of this publication may be reproduced, stored in a retrieval system, or transmitted, in any form or by any means, electronic, mechanical, photocopying, microfilming, recording or otherwise, without written permission of the publisher. A copy of this article is available from the publisher for $\$ 15.00$. 